ПОПЫТКИ ОППОНЕНТА ПОДТАСОВАТЬ ЛИЧНЫЙ ВКЛАД И ЗНАЧИМОСТЬ ИССЛЕДОВАНИЯ ОБ АЭРОПОРТАХ МВЛ

\author{
Леонтьев Рудольф Георгиевич \\ $\partial-р$ экон. наук, профессор, \\ почетный работник высшего профессионального образования РФ, \\ главный научный сотрудник ВЦ ДВО РАН, \\ 2. Хабаровск, Российская Федерачия
}

\title{
THE OPPONENT'S ATTEMPTS TO SCREAM PERSONAL CONTRIBUTION AND THE IMPORTANCE OF RESEARCH ABOUT MVL AIRPORTS
}

Leontyev R.G. Computer center of the Far East office Russian Academy of Sciences Khabarovsk, Russia DOI: $10.31618 /$ ESU.2413-9335.2020.4.76.919

\section{АННОТАЦИЯ}

В статье подвергнуты анализу представленные в отзыве официального оппонента (профессора) подтасованные им оценки личного вклада соискателя и практической значимости исследования менеджмента аэропортами местных воздушных линий. Доказано, что эти оценки являются не только фальсифицированной, но и вообще неуместной информацией, предназначенной для придания данному отзыву видимости высококвалифицированного документа государственной научной аттестации и тем самым запутать все экспертное сообщество и других представителей научной общественности о релевантности, рассмотренной оппонентом диссертации.

\section{ANNOTATION}

The article analyzes the assessments of the applicant's personal contribution and the practical significance of the study of the management of local airlines, presented in the review of the official opponent (professor). It has been proven that these assessments are not only falsified, but generally inappropriate information intended to give this review the appearance of a highly qualified document of state scientific certification and thereby confuse the entire expert community and other members of the scientific community about the relevance of the dissertation considered by the opponent.

Ключевые слова: Аэропорты, местные воздушные линии (МВЛ), государственная научная аттестация, диссертация, отзыв официального оппонента, фальсифицированные оценки, личный вклад соискателя, практическая значимость диссертации.

Key words: Airports, local airlines (MVL), state scientific attestation, dissertation, review by an official opponent, falsified assessments, personal contribution of the applicant, practical significance of the dissertation.

Между невежеством и знанием лежит пропасть.

Японская пословища

Известно, что в соответствии с пунктом 20 (абзац 1) действующего тогда "Положения о порядке присуждения ученых степеней”, утвержденного постановлением правительства РФ от 30 января 2002 года № 74 (в редакции постановления правительства РФ от 20 июня 2011 года № 475), «диссертационные советы назначают официальных оппонентов по диссертации «из числа компетентных в соответствующей отрасли науки ученыхху.

Однако, «диссертационный совет ДМ 223.005.02 при Морском государственном университете им. адм. Г.И. Невельского» по диссертации Милой назначил первым официальным оппонентом д.э.н., профессора, директора института международного бизнеса Владивостокского государственного университета экономики и сервиса (ВГУЭС) Латкина А.П., который ни по образованию, ни по роду научной и преподавательской деятельности и ни по областям его научных интересов никак не связан со сферой транспорта и, особенно, в области гражданской авиации. В 2012 году не были известны его "ваковские" и обычные научные публикации в этой же сфере.

Поэтому профессор Латкин А.П. в 2012 году не являлся «ученым, компетентным в соответствующей отрасли науки» (в сфере транспорта). При этом, забегая вперед, следует отметить, что именно это обстоятельство, не в последнюю очередь, предопределило неприемлемо отвратительное качество содержания его (как официального оппонента) отзыва на пресловутое «диссертационное исследование» соискателя ДВГУПС Милой.

Вместе с тем, известно, что согласно пункту 22 (абзац 2) действующего тогда "Положения о порядке присуждения ученых степеней”, утвержденного постановлением правительства РФ от 30 января 2002 года № 74 (в редакции постановления правительства РФ от 20 июня 2011 года № 475), «отзыв подписывается официальным оппонентом и заверяется печатью организациии, работником которой он являлся». Однако, вопреки данному требованию отзыв официального оппонента Латкина А.П., подписанный им 3 мая 2012 года, не был заверен печатью ВГУЭС, работником которого он являлся, и только поэтому 
данный отзыв уже оказался де факто недействительным и де юре ничтожным. Налицо либо головотяпство, допущенное Латкиным А.П. в силу его некомпетентности, либо сознательное нарушение им установленного порядка оформления отзывов, рассчитанное на недостаточную осведомленность руководства «диссертационного совета ДМ 223.005.02 при Морском государственном университете им. адм. Г.И. Невельского».

На этом анализ рассматриваемого здесь фальсифицированного отзыва официального оппонента Латкина А.П., уже сам по себе делающего незаконными защиту диссертации Милой и выдачу ей диплома кандидата экономических наук, следовало бы закончить, но, как говорится, «для чистоты эксперимента» представляется необходимым детально рассмотреть содержание этого отзыва, конкретные впечатления о котором могут охарактеризовать приведенные в настоящей монографии ниже негативные обстоятельства.

Для начала следует отметить, что в соответствии с пунктом 22 (абзац 1) "Положения о порядке присуждения ученых степеней”, утвержденного постановлением правительства РФ от 30 января 2002 года № 74 (в редакции постановления правительства РФ от 20 июня 2011 года № 475), «официальный оппонент на основе изучения диссертации и опубликованных работ по теме диссертации представляет в диссертационный совет письменный отзыв, в котором оцениваются актуальность избранной темы, степень обоснованности научных положений, выводов и рекомендаций, сформулированных в диссертации, их достоверность и новизна, а также дается заключение о соответствии диссертации критериям, установленных настоящим Положением».

Итак, в «диссертационный совет ДМ 223.005 .02 при Морском государственном университете им. адм. Г.И. Невельского» поступил «Отзыв официального оппонента д.э.н., проф. А.П. Латкина на диссертационную работу Милой Александры Витальевны на тему: «Управление инфраструктурой аэропортов малой интенсивности полетов, представленную на соискание ученой степени кандидата экономических наук по специальности 08.00.05 «Экономика и управление народным хозяйством (экономика, организация и управление предприятиями, отраслями, комплексами: транспорт)». Сразу следует констатировать, что уже в названии данного отзыва лично профессором, д.э.н. Латкиным А.П. были сделаны две грамматические ошибки (в этом названии следовало бы после слова «оппонента» поставить запятую, а словосочетание с двоеточием «на тему:» убрать вообще).

Указанный отзыв содержит следующие 6 разделов: «1. Актуальность темы исследования»; «2. Соответствие диссертации специальности совета»; «3. Обоснованность, достоверность и новизна научных выводов, положений и рекомендаций диссертации»; «4. Личный вклад и практическая значимость полученных автором результатов»; «5. Дискуссионные моменты и недостатки диссертации»; «7. Общая оценка диссертации». К великому сожалению, и здесь следует констатировать, что директор Института международного бизнеса и экономики ВГУЭС Латкин А.П. непростительно совершил элементарную арифметическую ошибку - не смог правильно подсчитать и обозначить цифрами шесть разделов своего пятистраничного отзыва - и явно халтурно «подмахнул» его не читая.

Проведенный в настоящей работе ниже критический анализ содержания раздела «4. Личный вклад и практическая значимость полученных автором результатов» отзыва официального оппонента Латкина А.П. позволил выявить следующие негативные обстоятельства.

Четвертый раздел отзыва официального оппонента Латкина А.П. - «4. Личный вклад и практическая значимость полученных автором результатов» - состоит из двух абзацев. И прежде чем в настоящей работе перейти к их поочередному рассмотрению в свете общепринятых требований к представлению документов государственной научной аттестации следует отметить в формулировке данного раздела «отзыва» Латкина А.П. следующие невязки:

- во-первых, в соответствии с пунктом 12 (абзац 1) «Положения о порядке присуждения ученых степеней», утвержденного постановлением правительства РФ от 30 января 2002 года № 74 (в редакции постановления правительства РФ от 20 июня 2011 года № 475), «организация, где выполнялась диссертация..., дает заключение по диссертации, в котором должны быть отражены... личное участие автора в получении результатов, изложенных в диссертащии, ... и практическая значимость ...»;

- во-вторых, и в соответствии с пунктом 23 (абзац 2) указанного "Положения о порядке присуждения ученых степеней”, «в отзыве ведущей организации отражается значимость полученных автором диссертащии результатов» и «должны также содержаться конкретные рекомендации по использованию результатов и выводов диссертациич»;

- в-третьих, а также в соответствии с пунктом 28 (абзац 1) указанного "Положения о порядке присуждения ученых степеней”, «диссертационный совет принимает... заключение по диссертации, в котором отражаются... научные результаты, полученные лично соискателем, ...их значение для... практики, рекомендации об использовании результатов диссертационного исследования»;

- в-четвертых, вместе с тем, согласно пункту 22 (абзац 1) указанного "Положения о порядке присуждения ученых степеней”, отзыв официального оппонента не должен содержать ни «личного вклада (участия) соискателя», ни «практической значимости полученных 
результатов», ни «рекомендаций по их использованию». Поэтому, учитывая вышеизложенные установленные требования, профессор Латкин А.П. явно неправомерно превысил свои полномочия, изложив в четвертом разделе своего «отзыва» личные оценки перечисленных в предыдущем подпункте характеристик «диссертационного исследования» соискателя ДВГУПС Милой. Налицо - еще один факт неосознанного постыдного незнания или сознательного преступно-халатного игнорирования профессором Латкиным А.П. положений основополагающих нормативноправовых актов государственной научной аттестации;

- в-пятых, на этом рассмотрение содержания четвертого раздела «отзыва» профессора Латкина А.П. можно было бы закончить, но, как говорится, «для чистоты эксперимента» его следует продолжить анализом его абзацев.

1. Первый абзац. В данном абзаце четвертого раздела своего «отзыва» профессор Латкин А.П. сообщает буквально следующее: «На основе изложенного выше в п. 3, считаю необходимым отметить заметный личный вклад соискателя А.В. Милой в решение заявленной научной проблемы, а также важную практическую значимость полученных автором результатов. Они могут быть использованы в практической работе не только аэропортов малой интенсивности полетов (АМИП) Хабаровского края, но и в деятельности АМИП других регионов страны».

Анализ содержания данного абзаца позволяет выявить следующие негативные обстоятельства:

- во-первых, данный абзац страдает грамматическими и фразеологическими ошибками. Так, употребление в предыдущем абзаце (последнем абзаце третьего раздела) словосочетания «в соответствии с вышеизложенным» и применение в данном абзаце словосочетания «на основе изложенного выще» представляется случаем проявления тавтологии. Запятая перед словом «считаю» явно лишняя. Употребление в данном абзаце выражения «отметить заметный», состоящего из двух однокоренных слов, также представляется проявлением тавтологии. После слова «заявленной» следует употребить местоимение «ею» или, лучше, словосочетание «в ее диссертации». Во избежание присутствующей во втором предложении данного абзаца, на этот раз, двойственной тавтологии это предложение следует в качестве придаточного присоединить к первому предложению и изложить его следующим образом: «которые могут быть использовань в практической деятельности аэропортов МВЛ не только Хабаровского края, но и других субъектов $P \Phi \gg$;

- во-вторых, профессор Латкин А.П. в всем своем «отзыве» так и не сообщил, какая, по его мнению, конкретная «научная проблема» была «заявлена и решена в диссертации Милой»?
Правильно ли эта «проблема» была поставлена («заявлена») соискательницей и насколько полно она была «решена» в ее диссертации? И поскольку сама Милая в своей диссертации и в ее автореферате так и конкретно не обозначила [1], якобы, «заявленную и решенную научную проблему», то похоже, что профессор Латкин А.П. снова предпочел озадачить этим все привлекаемое экспертное сообщество, «широкую научную общественность» и заинтересованных сотрудников Минобрнауки России;

- в-третьих, более того, на фоне «изложенного выше в п. 3» и данной неопределенности с «научной проблемой» совершенно непонятно, с какой-такой стати профессор Латкин А.П. весьма категорически и бесповоротно «счел необходимым отметить заметный личный вклад соискателя A.B. Милой в решение» неизвестной ему как оппоненту и другим экспертам, якобы, «заявленной научной проблемы»? Также непонятно, почему профессор Латкин А.П. с таким же рвением «счел необходимым отметить... важную практическую значимость полученных автором результатов»? Ведь «в вышеизложенном в $n$. 3» такие «результатыл» (впрочем, как и указанный «личнылй вклад») явно не просматриваются. Нет этого и в пресловутой «диссертации» Милой [1-3];

- в-четвертых, вместе с тем, утверждая, что упомянутые выше «результаты», якобы, «могут быть использованы в практической работе АМИП», профессор Латкин А.П. неоправданно не обозначил, какие конкретные «результаты» он имеет в виду? Где конкретно, когда, кем, в каких условиях, каким образом и с каким ожидаемым эффектом эти «результаты могут быть использованы»? То есть беспечно, небрежно и, в то же время, «фундаментально» ляпнув о голословной «заметности», мнимой «важности» и ложной «возможности использования» чего-то несуществующего в природе, профессор Латкин А.П., вероятно, считает, что одного его «авторитетного» слова вполне достаточно для беспрекословно положительного восприятия пресловутой «диссертации» Милой экспертным сообществом, «широкой научной общественности» и Минобрнауки России, отвечающим за государственную научную аттестацию;

в-пятых, и здесь остается лишь констатировать, что и в этом случае профессор Латкин А.П. решил путем безграмотного изложения данного абзаца своего «отзыва» глуповато и авантюрно соврать либо по своей простоте душевной, либо в силу деликтнорискового своекорыстия.

2. Второй абзац. В данном абзаце четвертого раздела своего «отзыва» профессор Латкин А.П. сообщает буквально следующее.

«Сформулированные в диссертации научные положения и организационнометодические рекомендации по разделению аэропортовой деятельности на основную и вспомогательную дает возможность вырабатывать обоснованные предложения по 
формированию наиболее эффективной стратегии развития авиационной компании и, тем самым, обеспечивать ей наиболее выгодную конкурентную позицию на рынке в целях достижения высоких финансовых результатов своей деятельности и позволяет оценить эффективность и результативность применения ГЧП в АМИП».

Анализ содержания данного абзаца позволяет выявить следующие негативные обстоятельства:

- во-первых, данный абзац тоже cmpaдaеm грамматическими и фразеологическими ошибками. Так, в данном абзаце вместо слова «дает» следовало бы употребить слово «дают». И поскольку выражение «тем самым» - это союз со значением следствия, то запятые после союза «и» и после слова «самым» следовало бы убрать. А после слова «формированию» следовало бы употребить словосочетание «и реализации», поскольку только «формирование стратегии» (без ее «реализации») не может обеспечить соответствующее «развитие». Затем вместо слова «позволят» следовало бы употребить слово «позволяют». Кроме того, употребление словосочетания «эффективность $u$ результативность» является невежественной тавтологией, поскольку «эффект» - это результат (чего-нибудь) [4];

- во-вторых, на самом деле Милая предложила в своей диссертации «разделение неавиационной аэропортовой деятельности», а не «разделение» всей «аэропортовой деятельности» (как это приврал Латкин А.П. в своем «отзыве»). И по этому поводу Милая никакие «научные положения $u$ организационно-методические рекомендациии» лично не «сформулировала» (как это опять приврал Латкин А.П.). Кроме того, Милая предложенное ею «разделение» в своей диссертации никак не связывала «авиационной компанией» (как это еще раз приврал Латкин А.П.). Тем более она даже не пыталась упоминать о «наиболее эффективной стратегии развития», «наиболее выгодной конкурентной позищии на рынке» и «высоких финансовых результатах» (о чем в очередной раз приврал Латкин А.П. в своем отзыве»), поскольку в своей диссертации с чужих слов не раз сообщала о непреодолимой убыточности КГУП «Хабаровские авиалинии» и его монопольном положении на МВЛ Хабаровского края. Налицо - множество фактов либо постыдного незнания Латкиным А.П. содержания диссертации и автореферата Милой, либо его сознательного неправомерного вранья и халтурного оппонирования;

- в-третьих, из содержания данного абзаца стало очевидным, что профессор Латкин А.П. совершенно, как говорят, «не курсе дела» относительно множества фактов, явлений и событий, которые он пытается в нем комментировать. Так, он позорно не знает о том, что с 2007 года одним из основных принципов управления в гражданской авиации [5,6] стало «разделение «объединенных» предприятий (каковым является КГУП «Хабаровские авиалинии») на независимые хозяйствующие субъекты - авиационные компании и аэропорты» и что этот принцип соблюдается во всех развитых странах мира. Поэтому какое-то «разделение аэропортовой деятельности» (и тем более «неавиационной» [7]) практически не касается какой-то «авиакомпании». Он не знает и о том, что перевозки на МВЛ северных районов Дальнего Востока РФ безнадежно убыточны и дотируются, поэтому там нет никакой «конкуренции» и «высоких финансовых результатов» (кстати, об этом сообщается и в диссертации Милой). Налицо - множество фактов удручающего невежества Латкина А.П. в сфере не только гражданской авиации, но и в экономике в целом;

- в-четвертых, вместе с тем в монографиях [1, с. 148-154] и [3, с. 138-157] довольно подробно обосновано, что «предложенное» Милой ничего не дающее простейшее арифметическое действие деление («разделение») на две части «неавиационной аэропортовой деятельности» - в научно-практическом смысле безусловно является, как говорят в народе, «чушью собачьей», и тем самым квалифицируется как самый неприглядный образчик несусветной глупости, неграмотно описанной и густо замешанной на вранье. То есть весьма смехотворной глупостью, которая в наибольшей степени должна раздражать российское научное сообщество (и не только российское).

Таким образом, изложенное во втором абзаце четвертого раздела «отзыва официального оппонента» Латкина А.П., казалось бы, «фундаментальное» утверждение являет собой образчик ужасающей безграмотности, фантастического вранья и некомпетентности, граничащих не только экспертной, но и профессиональной непригодностью. Вместе с тем, удивительно и в то же время прискорбно то, что здесь профессор Латкин А.П. в своем невежестве заметно превзошел уровень невежества пресловутого соискателя ДВГУПС Милой.

\section{Литература}

1. Леонтьев Р.Г. Диссертация об аэропортах МВЛ: кражи идей, вранье о результатах, невежество утверждений (как не надо представлять общую характеристику диссертации): монография / Р.Г. Леонтьев. - Владивосток: Дальневост. федерал. ун-т, 2017. - 190 с.

2. Леонтьев, Р.Г. Диссертация о малых аэропортах и нелегитимные заимствования из материалов краевого правительства (как не надо писать диссертацию): монография / Р.Г. Леонтьев. - Владивосток: Дальневост. федерал. ун-т, 2016. - 156 с.

3. Леонтьев Р.Г. Завиральные и невежественные байки из «диссертации» об аэропортах МВЛ: образчики профанации науки (как не надо представлять защищаемые положения диссертации): монография / Р.Г. Леонтьев. Владивосток: Дальневост. федерал. ун-т, 2017. $211 \mathrm{c}$. 
4. Ожегов С.И., Шведова Н.Ю. Толковый словарь русского языка. - М.: ООО "ИТИ Технология", 2003. - 944 с.

5. Концепция управления федеральным имуществом аэропортов (аэродромов) гражданской авиации. Приложение № 1 к приказу Минтранса России от 10 января 2007 г. № 5. - М.: Минтранс России, 2007. -20 с.

6. Концепция развития аэродромной (аэропортовой) сети российской федерации на период до 2020 года: [одобр. Правительством РФ 06 марта 2008 г.]. - Режим доступа: http://www.airportmagadan. ru/ru/predpr/index.html.

7. Волкова Л.П. Управление деятельностью аэропорта. Часть 2. Организационные основы управления: учебное пособие. - М.: ФГОУ ВПО «МГТУГА», 2007. - 105 с.

.А. Актуальные вопросы судебного прецедента как источника права // Право и политика. 2007. № 7. S. $84-91$

8. Алексеев С.С. Право: азбука - теория философия: опыт комплексного исследования. М.: , 2015. S. 78.

9. Марченко М.Н. Является ли судебная практика источником российского права? // Журнал российского права. 2000. № 12. S. 14-15.

10. Давид Р. Основные правовые системы современности. М., 1998. S. 301.

11. Власенко Н.А. Теория государства и права. Научнопрактическое пособие для самостоятельной подготовки студентов всех форм обучения. М., 2009. S. 125

12. Храпанюк В.Н. Теория государства и права. М., 1995. S. 185.

13. Нерсесянц В.С. Теория государства и права. М., 2001. S. 134
14. Гук П.А. Судебный прецедент как источник права. Дисс... канд.юрид. наук. Саратов. 2002. S. 68.

15. Подольская Н.А. К вопросу о понятии прецедента как источника права.// Судебная практика как источник права. М., 2000. С. 149.

16. Васильева Т.А. Актуальные вопросы судебного прецедента как источника права. Режим доступа://СПС: КонсультантПлюс

17. Алексеева Л.Б. Судебный прецедент: произвол или источник права? // Советская юстиция. 1991. №14. S. 2-3.

18. Меликова М. Правовая политика и актуальные проблемы законотворчества. Bak1 Universitetinin xəbərləri. 2009. №3. C. 25, 28, 29.

19. Cəfərov A. "Elmi məcmuələr" jurnal1. Bak1. 2016. Cild 18 №2. Aprel-iyun. S. 92.

20. Карнаушенко Л.В. Решения Конституционного Суда РФ в системе источников конституционного права.

https://cyberleninka.ru/article/n/resheniyakonstitutsionnogo-suda-rf-v-sisteme-istochnikovrossiyskogo-prava

21. Подтынников И.А. Является ли судебный прецедент источником права в России? // Вопросы студенческой науки. М. Выпуск №1 (17), январь 2018

22. Стругова Е.В. Судебный прецедент: реалии современной российской действительности. //Юридическая наука.М. 2016. № 2. С.38.

24.Жинкин А.А. Судебный прецедент в уголовном праве России. https://cyberleninka.ru/article/n/sudebnyy-pretsedentv-ugolovnom-prave-rossii

25. Гук П.А. Судебный прецедент: теория и практика. Москва, 2009. С.128.

\title{
ТЕХНОЛОГИЯ ОРГАНИЗАЦИИ ДИСТАНЦИОННОГО ОБУЧЕНИЯ В ЮРИДИЧЕСКОМ ОБРАЗОВАНИИ
}

\author{
Мухитдинова Фирюза \\ Доктор юридических наук, профессор \\ Ташкентского государственного юридического университета
}

\section{АННОТАЦИЯ}

В статье рассматриваются некоторые направления реформирования системы дистанционного образования. Изучены развитие процессов реформы в системе образования на современном этапе. Проанализированы международные проблемы и тенденции развития информационно-коммуникационных технологий обучения молодежи в онланй -режиме. Уделены внимания формирование коммуникативной компетенции при обучении коммуникационным технологиям будущих юристов в электронном образовательном пространстве. а также основные проблемы и тенденции развития дистанционного обучения в информационном обществе. Рекомендованы некоторые модели организации дистанционного обучения в юридическом образовании.

Ключевые слова: технология, модель, система, образования, дистанционно

Введение

В XXI веке приобрели научные исследования, связанные с изучением теоретических и практических аспектов становления и развития информационного общества. Основным условием его формирования стал новшество трансформации существующих социальных систем на принципах открытости. А также, происходящие реформы на современном этапе в системе образования тесно связаны с переходом к информационному обществу. Так как, вхождение Республики Узбекистан к 2030 году в состав 30 передовых стран мира по рейтингу оценки образовательных достижений учащихся PISA (The Programme for International Student Assessment); также принятым указом президента Узбекистана «Концепция 